NASA Technical Memorandum 103268

AIAA-90-2400

\title{
Combustor Technology for Future Aircraft
}

Robert R. Tacina

Lewis Research Center

Cleveland, Ohio

(NASA-TM-103268) COMRUSTOR TECHNOLOGY FOR
FUTURF AIPCRACT (IVASA) $17 \mathrm{P}$ CSCL $21 \mathrm{E}$
N91-14349

Unclas

63/07 0320430

Prepared for the

26th Joint Propulsion Conference

cosponsored by the AIAA, SAE, ASME, and ASEE

Orlando, Florida, July 16-18, 1990 
7n- - 


\title{
COMBUSTOR TECHNOLOGY FOR FUTURE AIRCRAFT
}

\author{
Robert R. Tacina \\ National Aeronautics and Space Administration \\ Lewis Research Center \\ Cleveland, Ohio 44135
}

\section{SUMMARY}

Advanced aircraft engines will increase the severity of the operating conditions of the combustor. Combustor inlet pressure and temperature increase as the overall engine pressure ratio increases. Further, temperature rise and the corresponding exit temperature also increase. This report describes future combustor needs and the technologies required to provide combustors for advanced aircraft engines. New fuel injectors with large turndown ratios which produce uniform circumferential and radial temperature patterns will be required. Uniform burning will be of greater importance because hot gas temperatures will approach turbine material limits. The higher combustion temperatures and increased radiation at high pressures will put a greater heat load on the combustor liners. At the same time, less cooling air will be available as more of the air will be used for combustion. Thus, improved cooling concepts and/or materials requiring little or no direct cooling will be required. Low emission combustor concepts will have to be developed. In particular, nitrogen oxides will increase substantially if new technologies limiting their formation are not evolved and implemented. For example, staged combustion employing lean, premixedprevaporized concepts or rich burn-quick quenchlean burn concepts could replace conventional single stage combustors.

\section{INTRODUCTION}

This report describes a research and development program for aircraft gas turbine combustors at the Lewis Research Center. The main objectives of the program are to provide the technology for higher operating temperature and pressure capability and for low nitrogen oxide $\left(\mathrm{NO}_{\mathrm{x}}\right)$ emissions and to provide numerical computer prediction methods.

Increasing the pressure and temperature of a gas turbine engine increases its thermodynamic efficiency and specific fuel consumption. This benefits direct operating cost as shown in figure 1 (see also ref. 1) (Note that the effect of compressor exit pressure is implied in the compressor exit temperature term of fig. 1.) The pacing technology for increased pressures and temperatures is the material limits. Thus, higher operating temperatures and pressures follow the development of higher performance materials. Extrapolations to future engine pressures and temperatures based on historical trends and cycle analysis (private communication with G. Knip of Lewis) are shown in figure 2.

Increases in the engine pressure and temperature levels affect the combustor in several ways. First, new fuel injectors with large turndown ratios which produce uniform circumferential and radial temperature patterns will be required. Uniform burning becomes more important because hot gas temperatures are approaching turbine material limits, and since more air will be required for the combustion process, less air will be available for tailoring the combustor exit temper- 

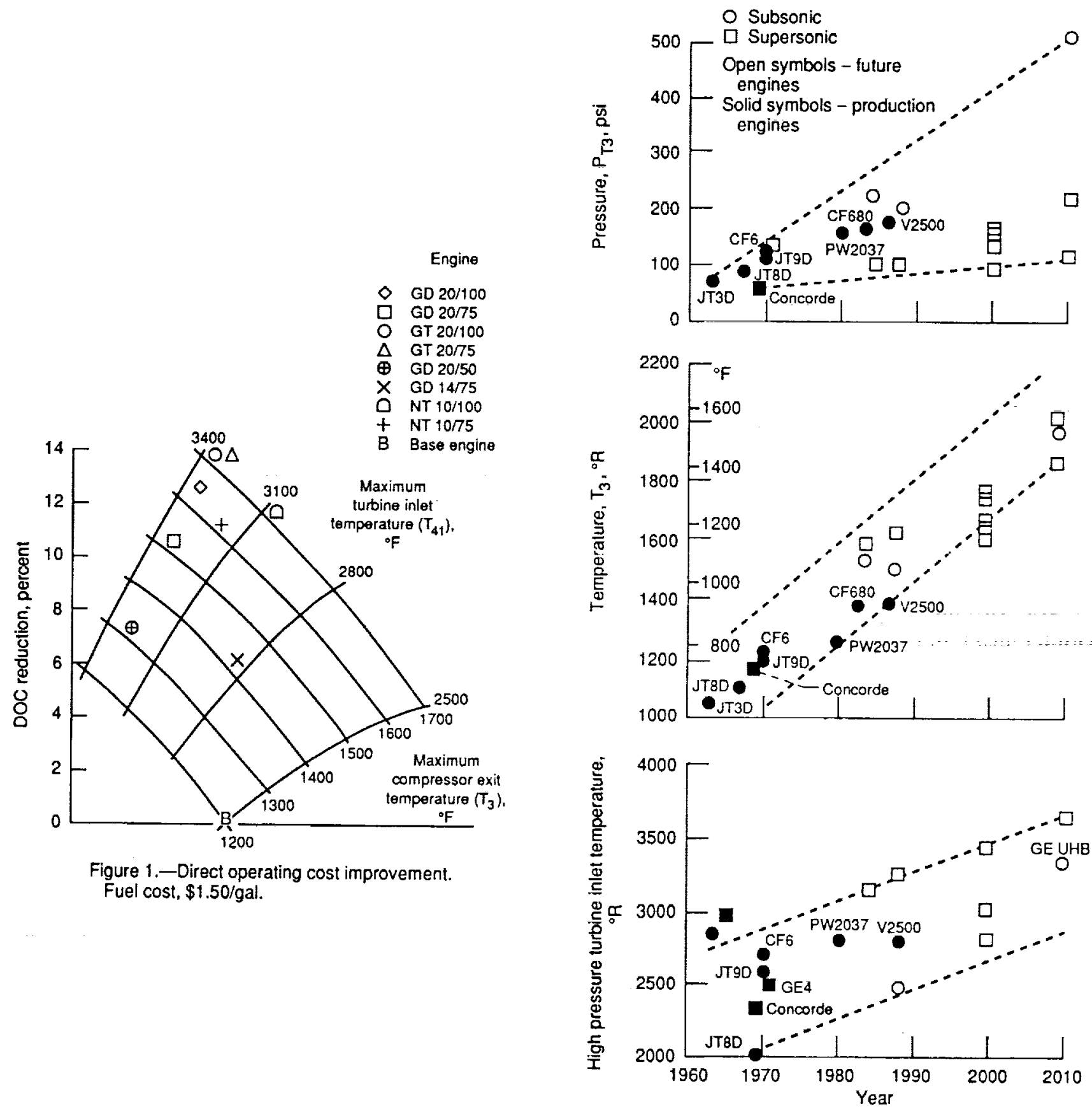

Figure 2.-Combustor inlet history at crulse conditions. 
ature profile. As the air temperatures and the combustion radiant thermal flux increase, the task of keeping the fuel flowing through the fuel injector within temperature limits becomes more difficult.

The higher combustion temperatures and increased radiation at higher pressures will put a greater heat load on the combustor liners. At the same time, less air will be available for cooling as more of the air will be used for combustion. Increased inlet air temperature decreases the heat sink capability of the air used for cooling and makes liner cooling more difficult. New and improved cooling concepts will therefore be required.

Increased temperatures and pressures result in higher emissions of nitrogen oxides $\left(\mathrm{NO}_{\mathbf{x}}\right)$. At altitudes above $60000 \mathrm{ft}$ where supersonic transports would fly, $\mathrm{NO}_{x}$ can react with ozone to reduce the levels of ozone (ref. 2). At lower altitudes where the subsonic fleet flies, the effect on ozone is negligible; however, $\mathrm{NO}_{x}$ are part of the reaction chain that results in smog and acid rain. The effects of $\mathrm{NO}_{x}$ from the subsonic fleet are small compared with the overall problem because airplanes use less than 1 percent of the fossil fuels. However, as the emissions from other sources are reduced, there is increasing concern for controlling the $\mathrm{NO}_{\mathrm{x}}$ emissions from airplanes.

Several programs at NASA Lewis address these problems. For small gas turbine engines, a joint program with the Army focuses on developing subcomponent technology for liner and fuel injectors. The technology will be applicable to large engines as well.

Research to control $\mathrm{NO}_{x}$ emissions is being done as part of the High Speed Research (HSR) Program, whose purpose is to develop the technology for an environmentally acceptable High Speed Civil Transport (HSCT). Of particular environmental concern are the $\mathrm{NO}_{x}$ emissions and the noise. The $\mathrm{NO}_{\mathrm{x}}$ emissions from a HSCT would be particularly harmful because the plane will fly in the stratosphere, where the effect of $\mathrm{NO}_{\mathrm{x}}$ on ozone is greatest. A reduction by a factor of 10 of the uncontrolled $\mathrm{NO}_{x}$ emissions is required to make the plane environmentally acceptable. The technology developed to control the NO emissions for the HSCT will be applicable (with some modifications) to the subsonic fleet.

Another research program at Lewis deals with development of numerical computer models. Until recently combustors have been developed primarily by empirical methods. However, computer models are becoming increasingly more useful in guiding development. There is great potential in further developing computer codes because of the ever increasing computer speed and storage, which when accompanied by improved solution algorithms and physics, can increase the accuracy and reduce the costs of using the computer models. This is contrasted with the increasing costs of experimental testing, particularly of full-scale hardware.

The remainder of the report describes in greater detail the research on subcomponents, $\mathrm{NO}_{x}$ emissions, and computer model development.

\section{SUBCOMPONENT TECHNOLOGY}

\section{Fuel Injection and Mixing}

Circumferential uniformity is important in preventing the formation of local rich zones and lean zones. Rich zones produce locally high temperatures, or hot spots, which reduce the life of turbine blades, or produce soot, which leads to higher radiant heat load to the combustor liners and to smoke emissions. Lean zones, particularly at low power conditions, can result in inefficient burning with resultant high unburned hydrocarbons and carbon monoxide emissions. Also, as the rise in temperature across the burner increases, more air is used in the burning process and less air is available for dilution and trimming of the temperature profile. An increased burner temperature rise results in a higher fuel-to-air ratio at high power. Thus, if the fuel-to-air ratio at low power is kept constant, the turndown ratio for the fuel injector increases. Another consideration is that as the heat load to the fuel injector increases, the temperature of the fuel in the injector increases if preventive measures are not taken. Since the fuel temperature in the injector is usually near maximum acceptable levels, any increase in fuel temperature will lead to gum and carbon formation.

Lewis has two projects to address these problems. One is a contract with the Allison Gas 
Turbine Division of General Motors to develop a fuel injector that improves the spray uniformity (as measured by the resulting burner exit temperature pattern factor), provides for a larger turndown ratio, and keeps the fuel temperature within acceptable limits. Table I (p. 15) lists the goals of the program. Allison will work cooperatively with two fuel injector manufacturers (Parker-Hannifin and Textron-Excello) to develop the fuel injector.

The development of an innovative, effervescent fuel injector is the objective of a grant with Professor A. Lefebvre of Purdue University. The effervescent fuel injector is shown in figure 3. A small amount of air, approximately 1 percent of the fuel flow rate, is mixed with the fuel before it is injected. When the air-fuel mixture is injected into the combustor, the air expands and shatters the fuel into small droplets. The resulting drop sizes are plotted in figure 4. A particularly useful feature of the injector is that the drop sizes are not a function of the fuel injector orifice diameter, thus allowing the use of large orifices that will be more tolerant of fouling.

\section{Liners}

Higher pressure ratios and turbine inlet temperatures not only increase the engine cycle efficiency, but also increase the severity of the liner thermal environment. As the combustor temperature increases, more air would be required for liner cooling if conventional film cooling were used. However, as the temperature rise increases, more air is required for combustion, thus leaving less for cooling. Also, increased pressure ratios increase the air temperature coming into the combustor from the compressor, thus reducing the heat sink capability of the cooling air. Consequently, improved use of the cooling air and/or new liner materials will be required.

Ceramics that can withstand combustor temperatures without the use of cooling air would be the ultimate material. However, ceramics are prone to stress failures induced by thermal shock. A joint NASA and Army program makes use of the high temperature capability of ceramics and reduces the thermal cyclic fatigue problem by spraying a ceramic on a pliable metal substrate.
The program objective is to develop a liner concept capable of withstanding combustor temperature levels of $1922 \mathrm{~K}\left(3000^{\circ} \mathrm{F}\right)$, while providing improved cyclic durability with little or no coolant flow.

The concept being investigated is called a compliant metal/ceramic CMC liner (fig. 5, from ref. 3 ). The liner concept consists of a plasmasprayed ceramic coat of yttria stabilized zirconia on a compliant nickel alloy substrate. This compliant metal substrate yields at low stress levels, thereby absorbing the differential expansion that develops between the metal and the ceramic as heat is applied. The compliant metal substrate was made from randomly oriented fibers which are sintered for strength. In particular, a Brunsbond Hoskins-875 compliant pad with a Hastelloy $\mathrm{X}$ metal substrate was used, and a NiCrAlY bond coat was used between the ceramic and the compliant metal substrate.

Results from an experimental study using the CMC concept (ref. 3 ) are shown in figure 6. The CMC liner is compared with a conventional splash film-cooled liner (SF) and two other advanced concepts, one a counterflow film-cooled liner (CFFC), and the other a simulated transpirationcooled liner (TRANS). The CFFC and TRANS configurations used from 40 to 50 percent less air than the conventional SF configuration, and the liner temperatures were 12 percent lower than the SF. The CMC liner coolant flow was 80 percent less than that of the SF, and the liner temperatures were 13 percent lower than the corresponding SF temperatures.

A more recent study done at Allison (ref. 4) under NASA/Army sponsorship confirmed the benefits of the CMC liner concept. Figure 7 compares the performance of the CMC liner with conventional film-cooled liners and advanced CFCC liners on the basis of coolant flow used per unit surface area. On this basis, the CMC liner uses 50 percent less wall cooling than the advanced wall cooling technology. The burner outlet temperature in this study was $2500^{\circ} \mathrm{F}$. The combustor is being modified to reach $3000^{\circ} \mathrm{F}$ burner outlet temperatures for further $\mathrm{CMC}$ liner testing. The pattern factor for these tests was 0.15 .

Coupons, or panels, of advanced ceramic and ceramic matrix liner materials will be tested at Lewis. Figure 8 is a schematic of the test facility 


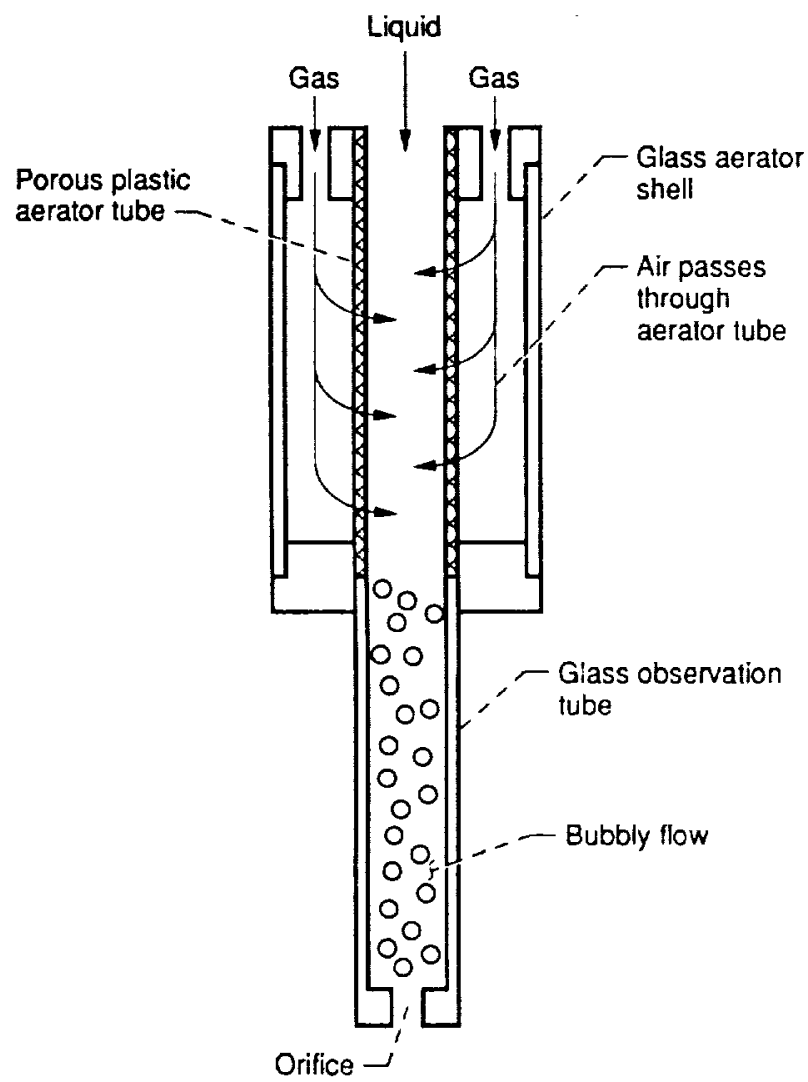

Figure 3.-EHervescent atomization.

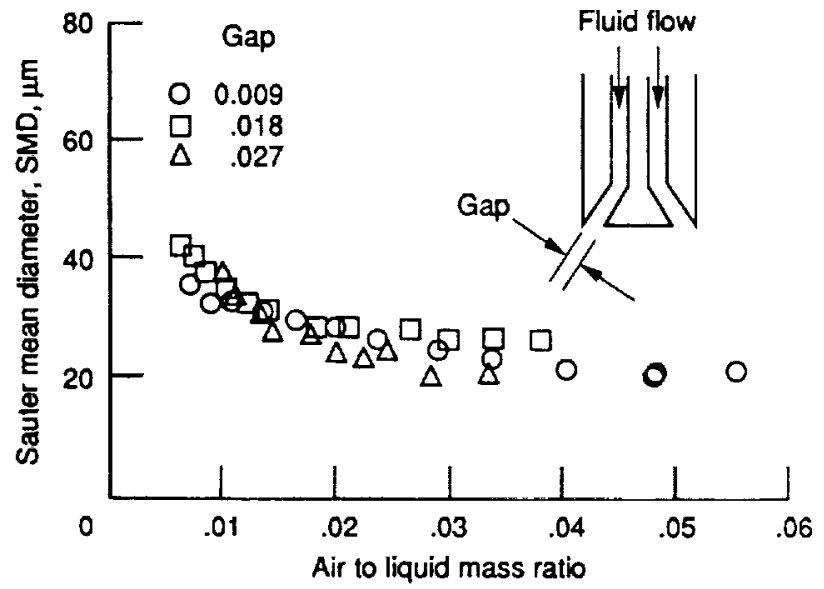

Figure 4.-Effervescent atomization.

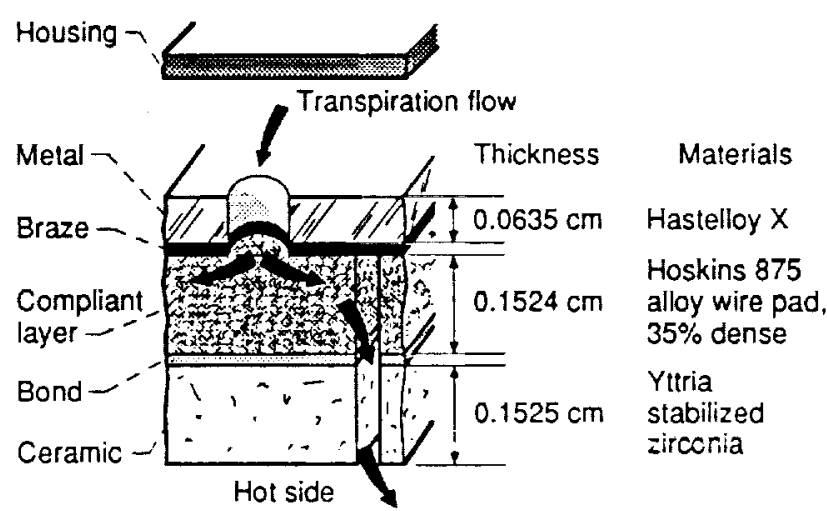

Figure 5.-Compliant metal liner concept.

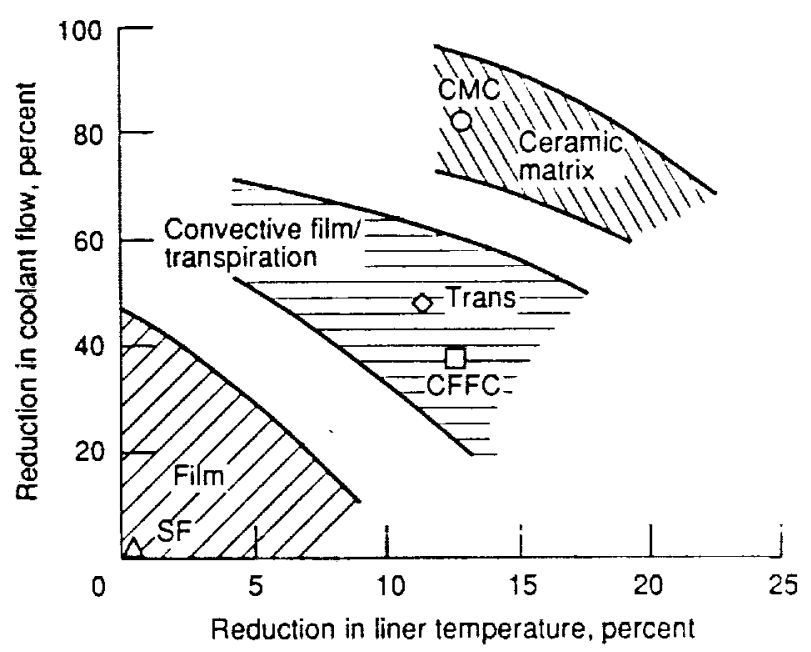

Figure 6.-Comparison of cooling effectiveness of a compliant metalveramic (CMC) liner, a counterflow film-cooled (CFFC) liner, a lamilloy (trans) liner, and a splash film (SF) liner.

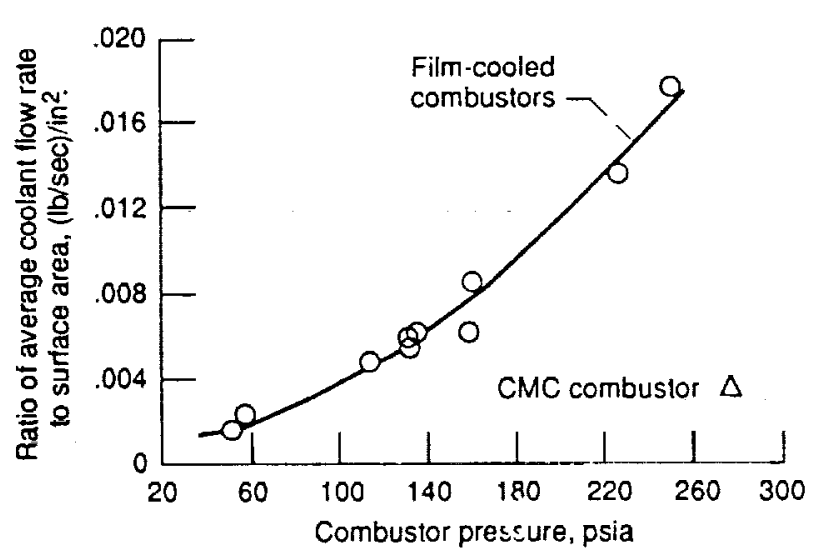

Figure 7.-Comparison of cooling effectiveness of a compliant metal/ceramic liner and a film cooled liner (Allison study). 
with the flow conditions listed (ref. 5). Coupon size is either 3.5 by 4 in. or 3.5 by 2 in. Eight or sixteen specimens can be tested at one time depending on the size. Cooling flow can be controlled to obtain material temperatures between 2000 and $3000^{\circ} \mathrm{F}$. The test facility should be complete in the last quarter of calendar year 1990. Initial liner materials to be evaluated include silicon nitride and carbon-carbon composites.

\section{EMISSIONS}

The important emissions from a gas turbine are, at low power conditions, carbon monoxide and unburned hydrocarbons from incomplete combustion and, at high power conditions, nitrogen oxides $\left(\mathrm{NO}_{\mathrm{x}}\right)$ and soot. Conventional combustors have been designed to provide high combustion efficiencies (99.9 percent), temperature profiles tailored to the turbine, minimum length, high stability, and altitude relight capability. This design has resulted in a slightly rich, diffusion flame primary zone with near maximum flame temperatures (see fig. 9). Unfortunately, burning at near maximum flame temperatures produces highest $\mathrm{NO}_{\mathbf{x}}$.

Emissions of $\mathrm{NO}_{x}$ are a function of combustor inlet air temperature, exit temperature, pressure, and residence time. Correlations of $\mathrm{NO}_{\mathbf{x}}$ emissions developed in the 1970's by NASA, General Electric, and Pratt \& Whitney (refs. 6 to 8 ) are shown in table II. (Note: the GE correlation does not have residence time (reference velocity) or exit temperature because they used the correlation to compare emissions within a family of engines, so that exit temperature and reference velocity did not change.) Extrapolations of the GE and Pratt \& Whitney $\mathrm{NO}_{\mathrm{x}}$ emissions trends as a function of inlet air temperature and pressure are shown in figure 10. The basis for the GE data is the $\mathrm{NO}_{\mathrm{x}}$ emissions from the NASA/GEAE ECCP (Experimental Clean Combustor Program), and the basis for the Pratt \& Whitney data is the PW2037. The strongest dependence is on inlet temperature, and approximately a $200 \mathrm{~K}$ increase in inlet temperature doubles the $\mathrm{NO}_{x}$ emissions.

The design of a low emission gas turbine combustor consists of a balance of providing enough time and sufficiently high temperatures to complete the hydrocarbon reactions (through flame product recirculation) and yet low enough time and temperatures to keep the formation of $\mathrm{NO}_{x}$ to a minimum. Since the formation rate of nitrogen oxides is an exponential function of temperature, $\mathrm{NO}_{x}$ occurs primarily at high power operation and will be particularly difficult to control as advanced engine cycles increase combustor inlet and exit temperatures. The emission levels of carbon monoxide and soot in present conventional engines are low at high power conditions, although they can be a problem at low power conditions such as idle. In the design of low $\mathrm{NO}_{x}$ combustors, that which decreases $\mathrm{NO}_{\mathrm{x}}$ usually increases $\mathrm{CO}$ or soot. However, because of other environmental considerations, carbon monoxide, unburned hydrocarbons, and soot must not be substantially increased.

Concepts that have experimentally demonstrated low emissions include the lean-premixed-prevaporized (LPP), the rich-burn/quickquench/lean-burn (RQL), and the lean-directinjection (LDI) combustors see (fig. 11). The LPP concept, the first to appear for controlling $\mathrm{NO}_{\mathrm{x}}$ in the early 1970's, is simple - provide a uniform mixture of fuel vapor and air that burns at low temperatures where $\mathrm{NO}_{\mathbf{x}}$ formation is a minimum. The disadvantages of the LPP are that it has narrow stability limits and is subject to auto-ignition and flashback. Emission data from the LPP flame tube experiments are given in references 9 to 15 .

The RQL concept was conceived to control $\mathrm{NO}_{x}$ from fuels containing nitrogen. In a leanburn system, nearly 100 percent of the fuel-bound nitrogen is converted into $\mathrm{NO}_{\mathrm{x}}$, whereas in a rich burn system, very little of the fuel-bound nitrogen is converted to $\mathrm{NO}_{\mathrm{x}}$. The rich-burn zone can be thought of as a fuel preparation zone. It is followed by quick mixing with the remaining combustion air in the quench zone. And, finally, in the lean-burn zone the burning process is completed at the relatively low temperatures where thermal $\mathrm{NO}_{x}$ formation is minimum. For fuels not containing nitrogen, the RQL offers the advantages of low $\mathrm{NO}_{\mathrm{x}}$ formation and the stability of a rich front end. References 16 to 19 describe the RQL combustor and provide emission data.

In the direct injection concept, all the combustion air enters the front end, and the fuel is 


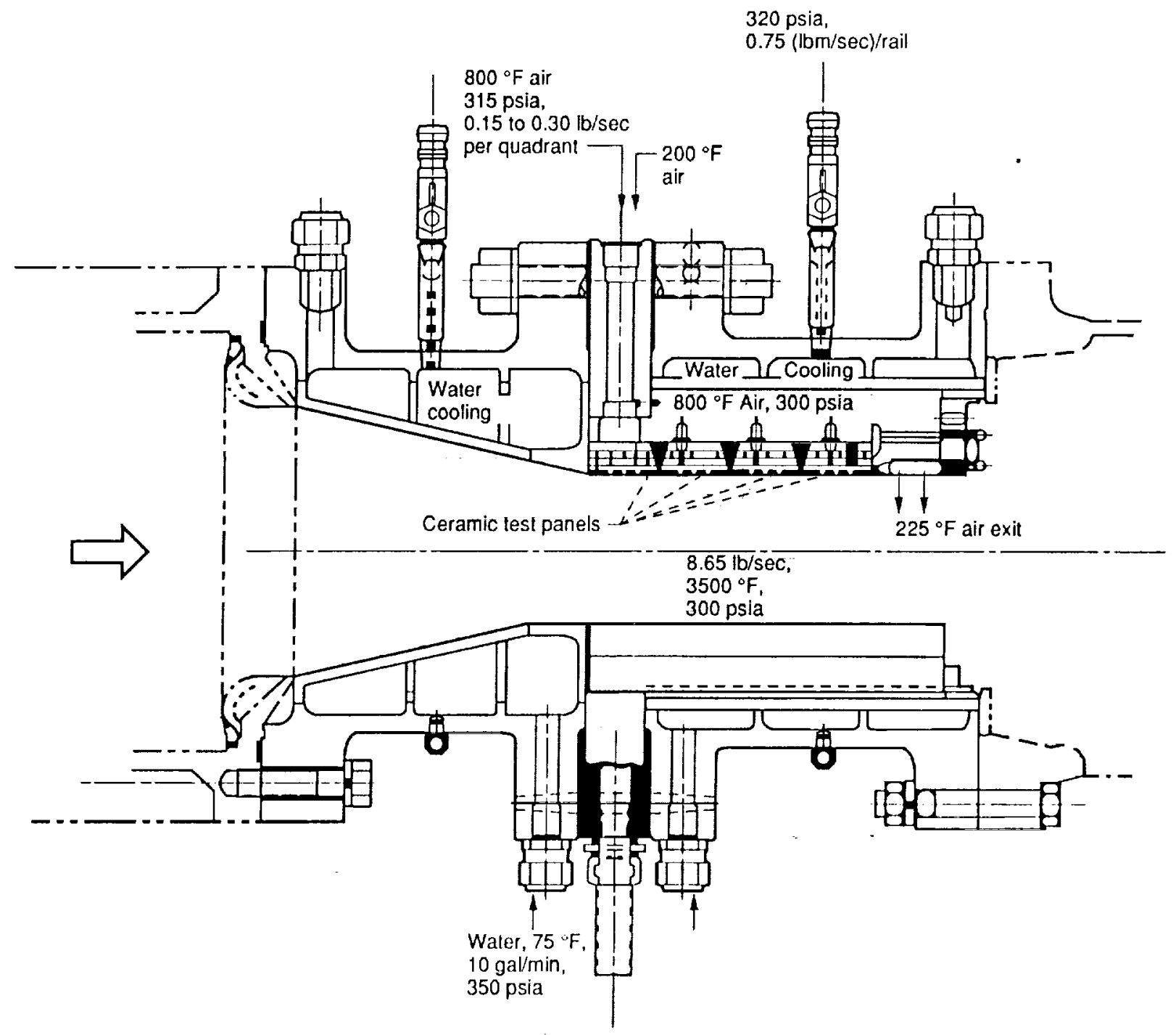

Figure 8.--Ceramic matrix wiar lesı rig layout.

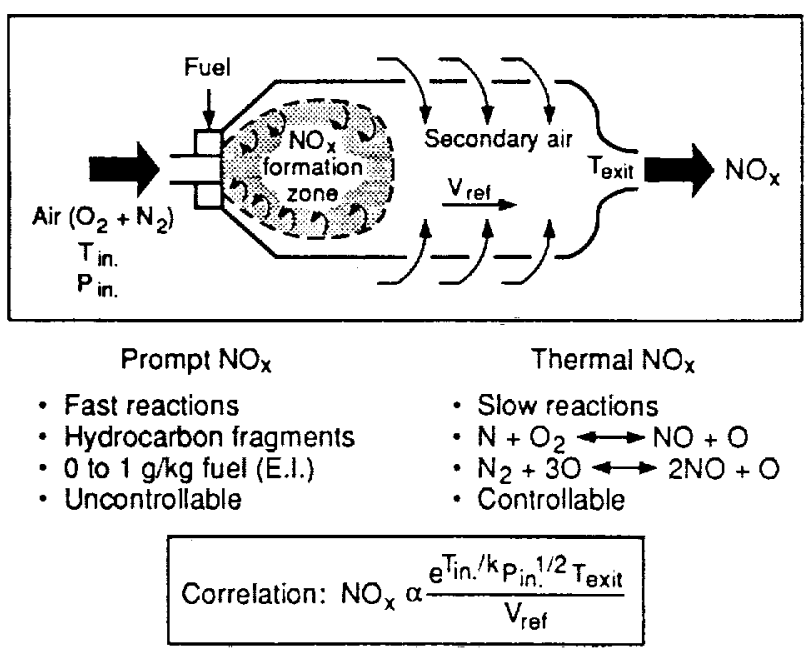

Figure 9.-Oxides of nitrogen. 
GE, NO $\mathrm{X}_{\mathrm{E}} \mathrm{El}-P_{3}^{0.4} \mathrm{e}^{\mathrm{T}_{3} / 194.4} e^{-\mathrm{Ho} / 53.2}$

- P\&W, NO $X, E I-\frac{P_{3}^{0.5} \mathrm{~T}_{4} \mathrm{e}^{T_{3} / 288} \mathrm{e}^{-\mathrm{Ho}_{0} / 53.2}}{V_{\mathrm{A}}}$

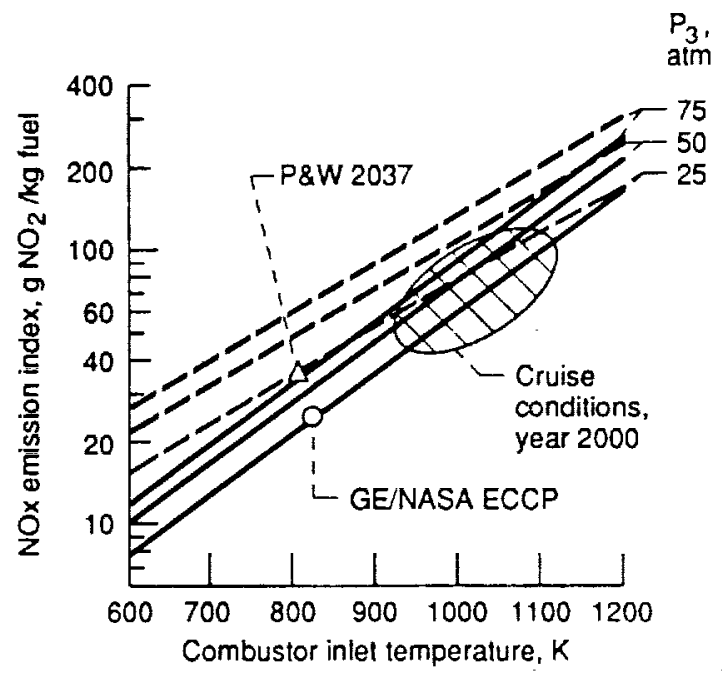

Figure 10.-Oxides of nitrogen as function of combustor inlet temperature and pressure; conventional diffusion flame temperature.

Lean, premixed, prevaporized (LPP)

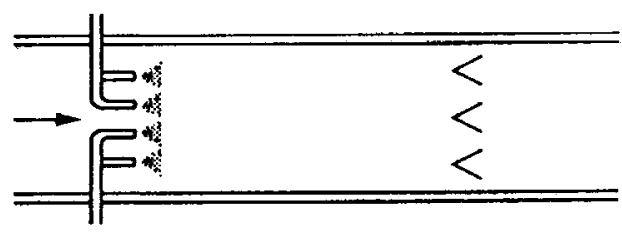

Rich burn-quick quench-lean burn (RQL)

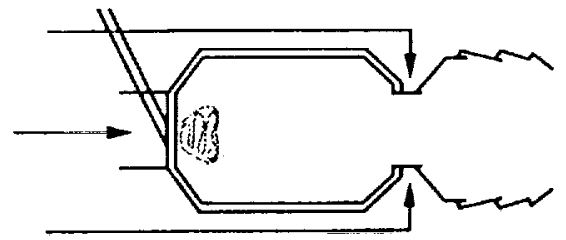

Lean, direct injection (LDI)

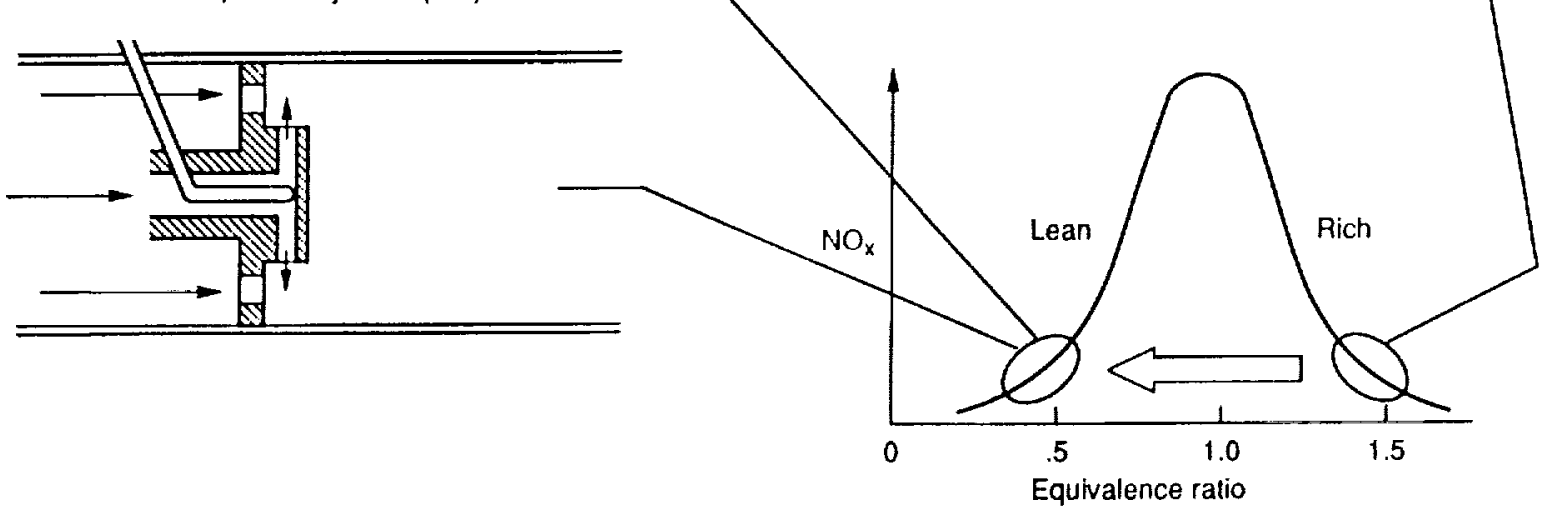

Figure 11.-Low $\mathrm{NO}_{x}$ combustor concepts. 
injected directly into the combustion zone. The fuel-air mixture is lean so that the burning temperature and $\mathrm{NO}_{\mathrm{x}}$ levels are low. No dilution air is used for cooling or for tailoring of the temperature profile. References 20 to 22 describe the LDI concept and provide emission data.

The $\mathrm{NO}_{\mathbf{x}}$ emissions obtained experimentally were correlated for the three concepts by the adiabatic combustion temperature over a wide range of inlet temperatures, pressures, and (lean) fuel-air ratios (see fig. 12 from ref. 23). The $\mathrm{NO}_{\mathrm{x}}$ emission index is an exponential function of adiabatic flame temperature. There was not a strong effect of inlet temperature; thus it was not considered an independent variable but is contained in its effect on adiabatic combustion temperature. No definite pressure effect was noticed. The $\mathrm{NO}_{\mathbf{x}}$ are also a function of time at the adiabatic combustion temperature; however, a simple correlation of $\mathrm{NO}_{\mathbf{x}}$ formation with time was not found.

Comparisons of the three concepts show that the lean-premixed-prevaporized (LPP) concept produces the lowest $\mathrm{NO}_{\mathrm{x}}$ emissions. However, the low $\mathrm{NO}_{x}$ potential of LPP is offset by the operational disadvantages of its narrow stability limits and its susceptibility to auto-ignition/flashback.

The rich-burn-quick-quench/lean-burn (RQL) concept has the advantage of good stability because of its rich zone, although variable geometry may be necessary. The higher $\mathrm{NO}_{x}$ emissions (compare with the LPP data) are probably due to the stoichiometric temperatures and production of $\mathrm{NO}_{\mathrm{x}}$ during the quench step. Chemical kinetics calculations show that only a small amount of $N_{x}$ is produced in the rich zone and that the $\mathrm{NO}_{\mathrm{x}}$ produced in the lean zone is approximately the same as the LPP. It is likely that innovative quick-quench mixing schemes can significantly reduce the overall $R Q L \mathrm{NO}_{x}$ levels.

The LDI concept produced nearly the same low levels of $\mathrm{NO}_{x}$ as using the LPP concept. A major advantage of the LDI concept is that it has the stability of conventional combustors. Because these results were obtained primarily with gaseous fuels, the challenge will be to produce the same low levels of $\mathrm{NO}_{\mathbf{x}}$ with liquid fuels.

The $\mathrm{NO}_{\mathrm{x}}$ emissions from conventional diffusion flame combustors are compared with the LPP combustor $\mathrm{NO}_{x}$ emissions in figure 13. The conventional combustor $\mathrm{NO}_{x}$ emissions values are based on the data correlations in table II. The calculations were made by increasing the inlet temperature and exit temperature by the same amount and determining the change in the $\mathrm{NO}_{x}$ emission index. For example, with the GE data the exit temperature plotted is equal to the inlet temperature plus a temperature rise of $790 \mathrm{~K}$. For simplicity, the pressure effect is ignored.

The $\mathrm{NO}_{\mathrm{x}}$ emission levels are approximately an order of magnitude greater for the conventional combustors than for the LPP flame tube combustors. The reason for this is that in the diffusion flame combustor, the fuel is injected into the primary zone where it is burned at near stoichiometric flame temperatures, then the gas temperature is reduced through the addition of dilution air to the combustor exit temperature. In the LPP combustor, the fuel is burned in a lean mixture at a much lower temperature, which produces less $\mathrm{NO}_{\mathrm{x}}$.

Conventional combustors must operate over the entire duty cycle and thus represent a compromise design that can operate efficiently at both low power and high power conditions. Low $\mathrm{NO}_{\mathrm{x}}$ combustors, such as the LPP, have narrow stability limits and will not be able to operate over an entire engine cycle. Thus, staged or parallel burners may have to be used. One approach is the RQL combustor with a rich zone for stability and a lean zone for low $\mathrm{NO}_{\mathbf{x}}$. Another approach, shown in figure 14, incorporates two burners: The first is a pilot stage, designed for maximum stability for low power conditions; the second is the main stage, designed for operation at high power conditions. The main stage burner can then be optimized for low $\mathrm{NO}_{\mathrm{x}}$ production within its narrow operation range. At low power conditions only the pilot burner is operated, and at high power conditions the main burner will be fueled with or without the pilot burner fueled.

To implement this program we have in-house and contract activities. The effort at Lewis consists of experimental flame tube studies of the LPP and RQL concepts. The LPP experiment is operational and preliminary data have been taken. The RQL experiment should be operational in the fourth quarter of 1990 . A variation of the RQL concept that uses a catalyst in the rich zone will also be evaluated. The catalyst will 


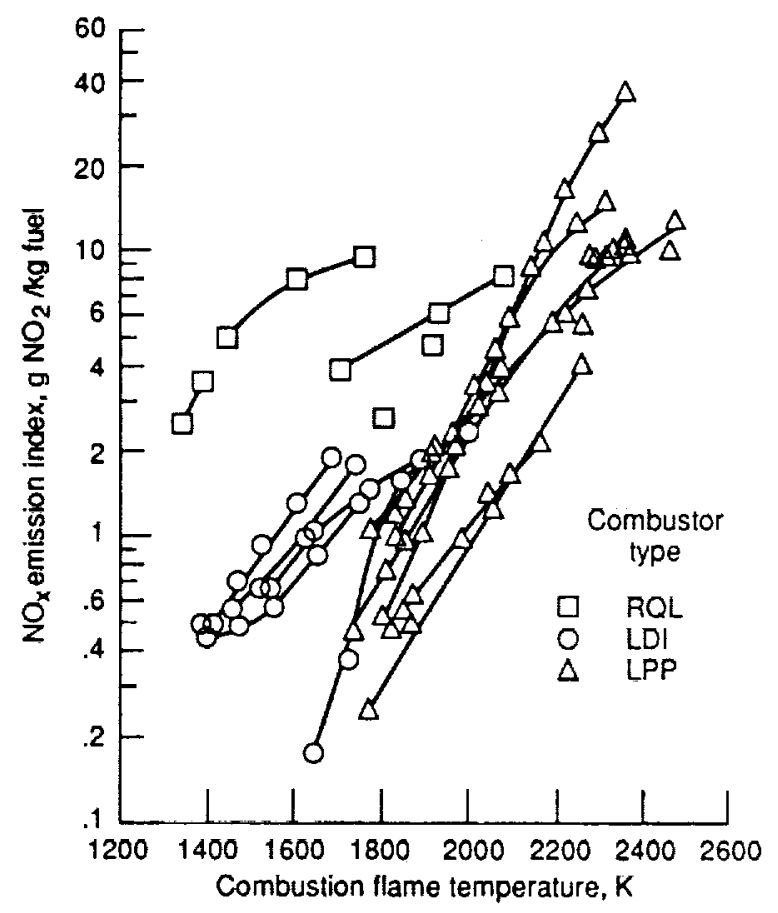

Figure 12.-Oxides of nitrogen from LPP, RQL, and LDI flame lube combustors.

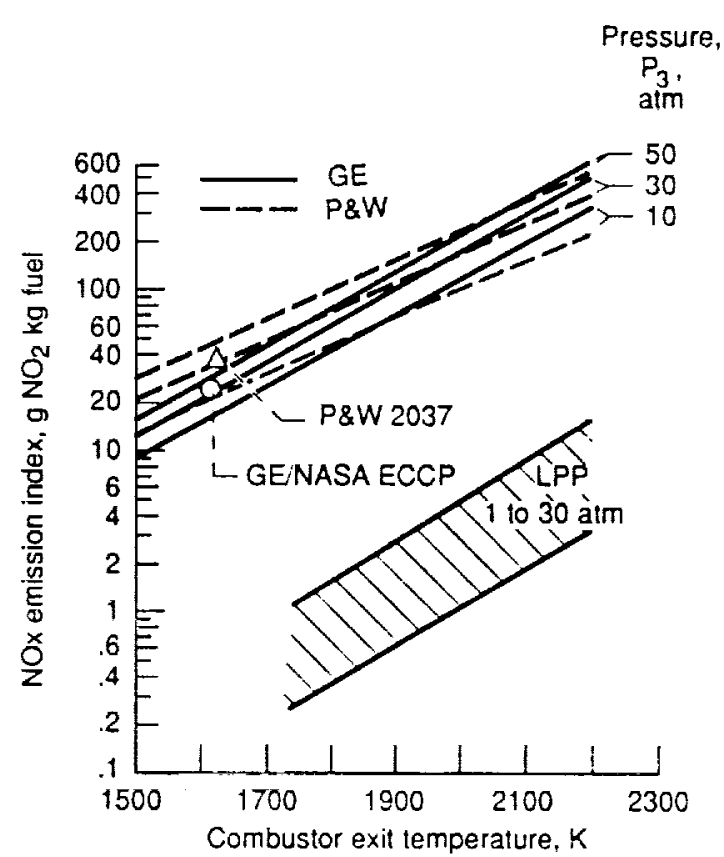

Figure 13.-Comparison of state-of-the-an diffusion flame combustors with LPP flame tube data.

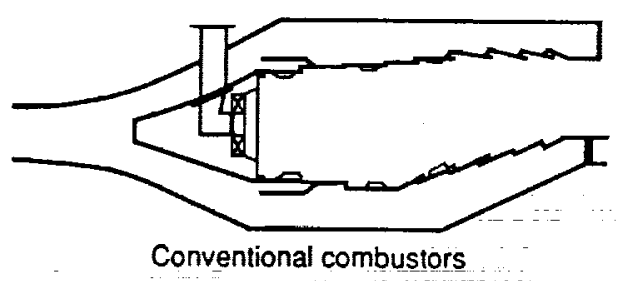

Single burning zones, film-cooled louver liners,

fuel rich burning zones, single-point fuel injection. fixed geometry

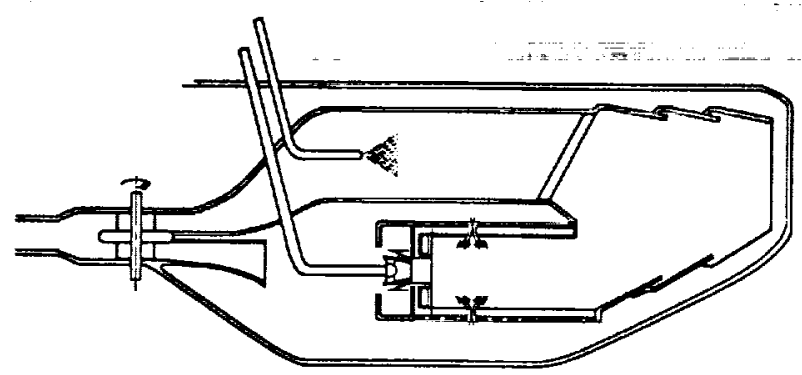

Future combustors

Multiple burning zones, advanced liner cooling, lean burning zones, multiple-point fuel injection, variable geometry

Figure 14.-Comparison of current and fulure combustors. 
allow the rich zone to be run at much higher equivalences than the conventional $R Q L$ rich zone equivalence ratio of $\mathbf{1 . 6}$.

At the University of California-Irvine RQL flame tube experiments will be performed in which advanced diagnostics will provide very detailed information on combustion processes. To take the technology beyond the flame tube stage to the development of combustors, contracts have been recently signed with General Electric, Pratt \& Whitney, and Allison. The goal of this effort will be to demonstrate, by 1995 , combustors that reduce $\mathrm{NO}_{\mathrm{x}}$ emissions by 90 percent from uncontrolled levels.

\section{COMPUTATIONAL METHODS}

The development of computational numerical computer models to predict combustor performance is an area of research at Lewis that has great potential benefits. The advantages of such methods are that they can provide detailed analyses of temperatures and emissions at low cost and with short turnaround times and can be evaluated with actual operating conditions. However, at present, computer modeling of a combustor is a qualitative tool that is time-consuming and expensive and requires experienced personnel to operate.

The objective of this effort is to develop and use computer models that will analyze and design combustor components and subcomponents, to understand the physics, and to determine how to optimize the design to improve perfor-mance.

The approach is to improve code capabilities for modelling the physics and chemistry and to improve the numerical method of solution and then to use test cases and measurements from experiments for code validation.

Two parallel model developments are being pursued: One is the modification of a Los Alamos code (KIVA II) developed for intermittent internal combustion engines for use with gas turbines; the other is the development of a model for gas turbine combustors by Carnegie Mellon University under the sponsoreship of Lewis. Figure 15 lists the activities sponsored by Lewis. The activities consist primarily of grid development, spray modeling and fuel-air mixing, and the addition of chemical kinetics to the models.

Figure 16 shows the prediction of a swirling fuel spray in a nonreacting air stream using the KIVA II code and a comparison with the experimental results. The predictions agree very well with the data. Fuel injection and mixing become increasingly important as more air is used for the combustion process and less is available for trimming of the temperature profile to the turbine. Detailed models of the interaction of the swirler and the fuel injector can provide valuable insight into the effect of different variables that presently can only be evaluated experimentally on a global scale.

Much work remains to be done before numerical computer models can be used to model combustors and replace experimental testing. First, to represent a combustor accurately, one hundred thousand to one million grid points are required. Setting up this grid is time-consuming. Second, the computational time needed to solve the discretized equations can be very long even on supercomputers (tens of hours of CPU time on a Cray). Besides the actual computer time spent to solve the problem, time-sharing increases the turnaround time.

Lastly, although mathematical models of the physics of the problem in some cases are very accurate, in other cases they are only a very approximate solution. Improved turbulence models will be needed to solve the complex flow situations that exist in a combustor. Added to this is the combustion/turbulence interaction, which is especially important for $\mathrm{NO}_{x}$ control. Combustion occurs on a molecular scale, but the mixing of vaporized fuel and air is affected by macroscopic fluid structures (turbulence). This requires modeling on both a molecular and macroscopic scale with a highly nonlinear functional dependence between species concentrations, temperature, and density.

The turbulence and computational problems are not unique to combustors but are general problems in internal computational fluid mechanics (ICFM). The ICFM program at Lewis is working to solve these problems. There are programs to automate the grid generation, to develop more efficient algorithms to solve the equations, and to develop improved turbulence models. 


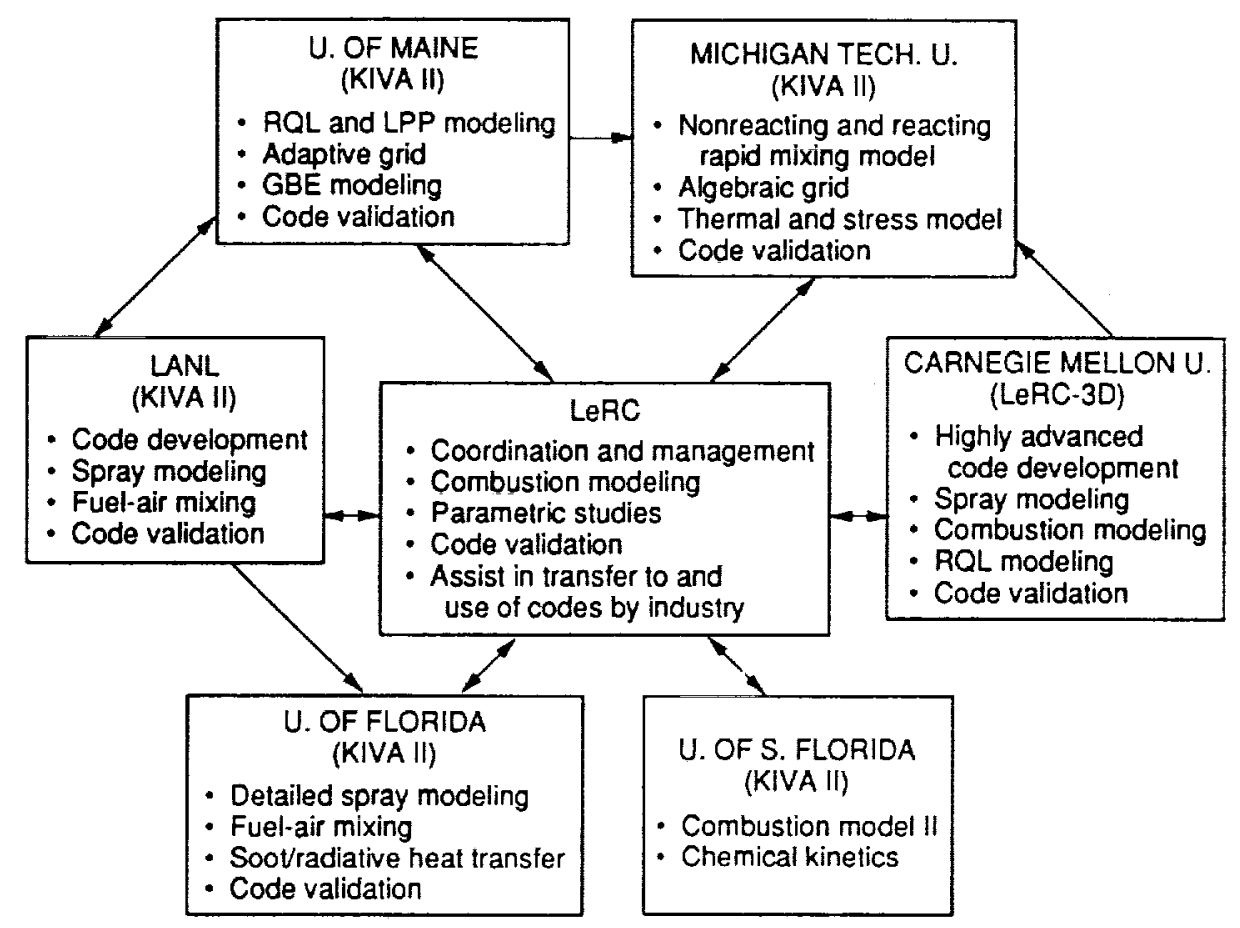

Figure 15.-Aerothermal analytical research $\mathrm{HSR}$ low $\mathrm{NO}_{\mathrm{x}}$ and small gas turbine engine.

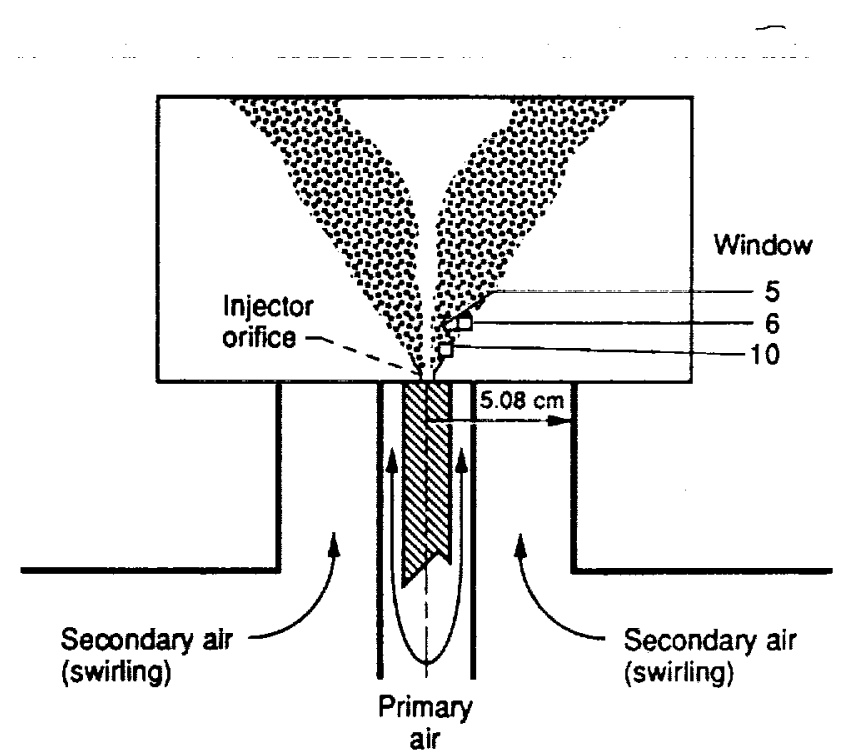

(a) Experimental rig.

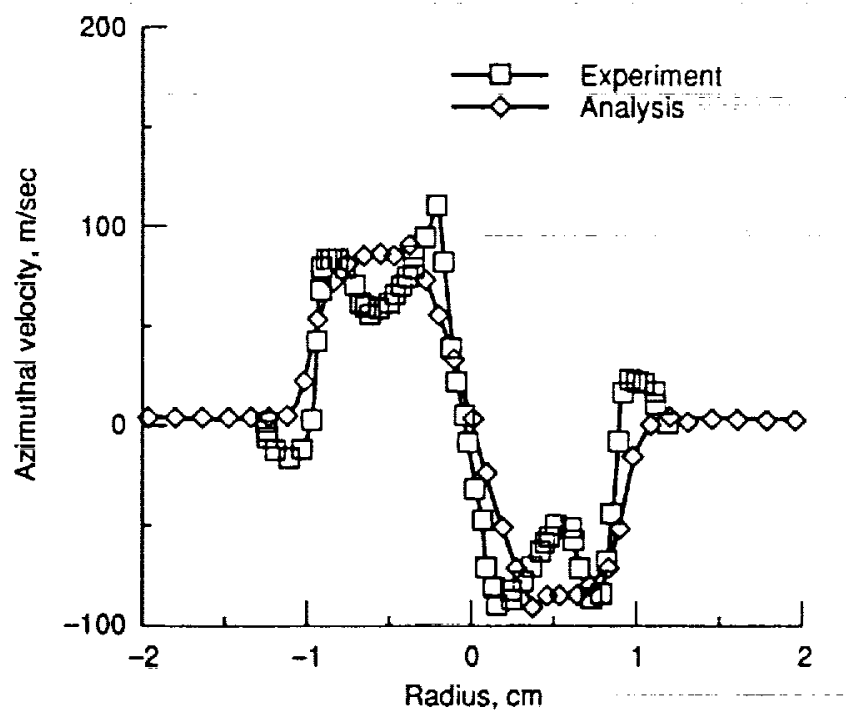

(b) KIVA azimuthal velocity comparison.

Figure 16.-Comparison of experimental fuel spray results with KIVA II code predictions. 


\section{CONCLUDING REMARKS}

Increased temperatures and pressures will make the aircraft gas turbine more efficient and reduce costs. The increased temperatures and pressures will present new challenges to the combustor design, including combustor durability and acceptability of the pattern factor for the durability of the turbine. The $\mathrm{NO}_{\mathrm{x}}$ emissions will also increase as the pressures and temperatures in the combustor increase. New combustor designs that employ staged combustion must be developed if the emissions are to be reduced substantially below the uncontrolled levels. However, it should be kept in mind that even though the emissions are discussed in terms of concentrations or emission index, a more meaningful emission criterion for aircraft application is the amount of pollutant per passenger seat mile. Thus, substantial improvements in emissions per passenger seat mile can be made by increasing the fuel efficiency of the engine even if the emissions are held to their present levels. The goal of the HSR program is not to merely hold $\mathrm{NO}_{\mathrm{x}}$ to present levels, but to go beyond that by reducing the cruise $\mathrm{NO}_{x}$ levels to near theoretical levels or about one-tenth of the uncontrolled levels.

Present high quality fuels should be available for the near future, and thus there is not a current program in fuels research. However, based on previous research, provisions for utilization of lower quality, broader specification fuels should also be considered.

\section{REFERENCES}

1. Smith, C.J., "Material Requirements for a 21st Century Ultra High Bypass Engine," Advanced High Temperature Engine Materials Technology Program, NASA CP-10039, 1989.

2. Johnston, H.S., Kinnison, D.E., and Wuebbles, D.J., "Nitrogen Oxides from High-Altitude Aircraft: An Update of Potential Effects on Ozone," Journal of Geophysical Research, Vol. 94, pp. 16351-16363.

3. Acosta, W.A., and Norgren, C.T., "Small Gas Turbine Combustor Experimental Study: Compliant Metal/Ceramic Liner and Performance
Evaluation," NASA TM-87304, 1986.

4. Paskin, M.D., Ross, P.T., Mongia, H.C., and Acosta, W. A., "Composite Matrix Cooling Scheme for Small Gas Turbine Combustors," AIA A Paper 90-2158, 1990.

5. Acosta, W.A., "Liner Cooling Research at NASA Lewis Research Center," AIAA Paper 87-1828, June 1987 (also NASA TM-100107 and AVSCOM TR 87-C-8).

6. Niedzwiecki, R.W., and Jones, R.E.,"Parametric Test Results of a Swirl-Can Combustor," NASA TM X-68247,1973.

7. Gleason, C.C., and Bahr, D.W.,"Experimental Clean Combustor Program (ECCP), Phase III Commercial Aircraft Turbofan Engine Tests with Double Annular Combustor," NASA CR-185384, 1979.

8. Sarli, V.J., Eiler, D.C., and Marshall,R.L., "Effects of Operating Variables on Gaseous Emissions," Presented at the Specialty Conference on Air Pollution Measurement Accuracy as it Relates to Regulation Compliance, New Orleans, LA, Oct. 28-28, 1975.

9. Anderson, D., "Effect of Equivalence Ratio and Dwell Time on Exhaust Emissions from an Experimental Premixing Prevaporizing Burner," NASA TM X-71592, 1974.

10. Roffe, G., and Venkataramani, K.S., "Emission Measurements for a Lean Premixed Propane/Air System at Pressures up to 30 Atmospheres," NASA CR-159421, 1978.

11. Semerjian, H., and Vranos, A., "NO ${ }_{x}$ Formation in Premixed Turbulent Flames," Sixteenth Symposium (International) on Combustion, American Chemical Society, Pittsburgh, PA, 1977, pp. 169-178.

12. Cooper, L.P., "Effect of Degree of Fuel Vaporization Upon Emissions fora Premixed Partially Vaporized Combustion System - for Gas Turbine Engines," NASA TP-1582, 1980.

13. Tang, S.-K., and Churchill, S.W.,"The Formation of Thermal and Fuel NOx for Radially Stabilized Combustion," Eighteenth Symposium (International) on Combustion, American Chemical Society, Pittsburgh, PA, 1981, pp. 73-79.

14. Anderson, D.N., "Effect of Premixing on Nitric Oxide Formation," NASA TM X-68220, 1973.

15. Semerjian, H.G., Ball I.C., and Vranos A., "Pollutant Emissions from 'Partially' Mixed Turbulent Flames," Seventeenth Symposium (International) on Combustion, American Chemical Society,Pittsburgh, PA, 1979, pp. 679-686.

16. Schultz, D.F., and Wolfbrandt, G., "Flame Tube 
Parametric Studies for Control of Fuel Bound Nitrogen Using Rich-Lean Two Stage Combustion," NASA TM-81472, 1980.

17. Rosfjord, T.J., "Evaluation of Synthetic-FuelCharacter Effects on Rich-Lean Stationary-GasTurbine Combustion Systems. Volume 1: Subscale Test Program," EPRI-AP-2822-Vol-1, Feb. 1983. (Avail. NTIS, DE83-901452X).

18. Novick, A.S., and Troth, D.L., "Low NO $\mathrm{N}_{x}$ Heavy Fuel Combustor Concept," NASA CR-165367, 1981.

19. Lew, H.G., Carl, D.R., Vermes, G., DeZubay, E.A., Schwab, T.A., and Prothroe, D., "Low NO $x$ Heavy Fuel Combustor Concept Program. Phase 1: Combustion Technology Generation,"
NASA CR-165482 (also DOE/NASA/0146-1), 1981.

20. Anderson, D.N., "Ultra-Lean Combustion at High Inlet Temperatures," ASME Paper 81-GT-44, Mar. 1981.

21. Alkabie, H.S., Andrews, G.E., and Ahmad, H.T., "Lean Low NO Primary Zones Using Radial Swirlers," ASME Paper 88-GT-245, June 1988.

22. Hussain, U.S., Andrews, G.E., Cheung, W.G., and Shahabadi, A.R., "Low No $\mathrm{No}_{x}$ Primary Zones Using Jet Mixing Shear Layer Combustion," ASME Paper 88-GT-308, June 1988.

23. Tacina, R.R., "Low NO $\times$ Potential of Gas Turbine Engines," AIAA Paper 90-0550, Jan. 1990 (also NASA TM-102452). 
TABLE I. - ADVANCE FUEL INJECTOR PROGRAM, TEST CONDITIONS AND GOALS

Test conditions:

Inlet pressure, atm ............25 to 50

Inlet temperature, $\cdot \mathbf{F} \ldots \ldots \ldots$. . . . 900 to 1450

Exit temperature, $\cdot F \quad \ldots \ldots \ldots 2800$ to 3600

Engine size, hp ... . . . . . . . . 1500 to 3500

Performance goals:

Efficiency (at all power conditions) $\ldots \ldots \ldots>>99.95$

Pattern factor . . . . . . . . . . . . . $<0.12$

SAE smoke number . . . . . . . . . . . $<25$

Lean blow out fuel to air ratio . . . . . . . 0.003

TABLE II. - NO ${ }_{x}$ CORRELATIONS

\begin{tabular}{|l|l|}
\hline General Electric & $\begin{array}{r}\mathrm{NO}_{\mathrm{x}_{\mathrm{EI}}}=23.8\left(\frac{\mathrm{P}_{3}}{432.7 \mathrm{psia}}\right)^{0.4} \exp \left(\frac{\mathrm{T}_{3}-1027.6^{\circ} \mathrm{F}}{349.9^{\circ} \mathrm{F}}+\frac{6.29-\mathrm{H}_{\mathrm{o}}}{53.2}\right) \\
=0.367\left(\mathrm{P}_{3}, \mathrm{~atm}\right)^{0.4} \exp \left(\frac{\mathrm{T}_{3}, \mathrm{~K}}{194.4}-\frac{\mathrm{H}_{\mathrm{o}}}{53.2}\right)\end{array}$ \\
\hline Pratt \& Whitney & $\mathrm{NO}_{\mathrm{x}_{\mathrm{EI}}} \propto \frac{\mathrm{P}_{3}^{0.5 \mathrm{~T}_{4}}}{\mathrm{~V}_{\mathrm{ref}}} \exp \left(\frac{\left(\mathrm{T}_{3}, \mathrm{~K}\right.}{288}-\frac{\mathrm{H}_{\mathrm{o}}}{53.2}\right)$ \\
\hline NASA & $\mathrm{NO}_{\mathrm{x}_{\mathrm{EI}}} \propto \frac{\mathrm{P}_{3}^{0.5 \mathrm{~T}_{4}} \exp \frac{\mathrm{T}_{3}, \mathrm{~K}}{288}}{\mathrm{~V}_{\mathrm{ref}}}$ \\
\hline
\end{tabular}




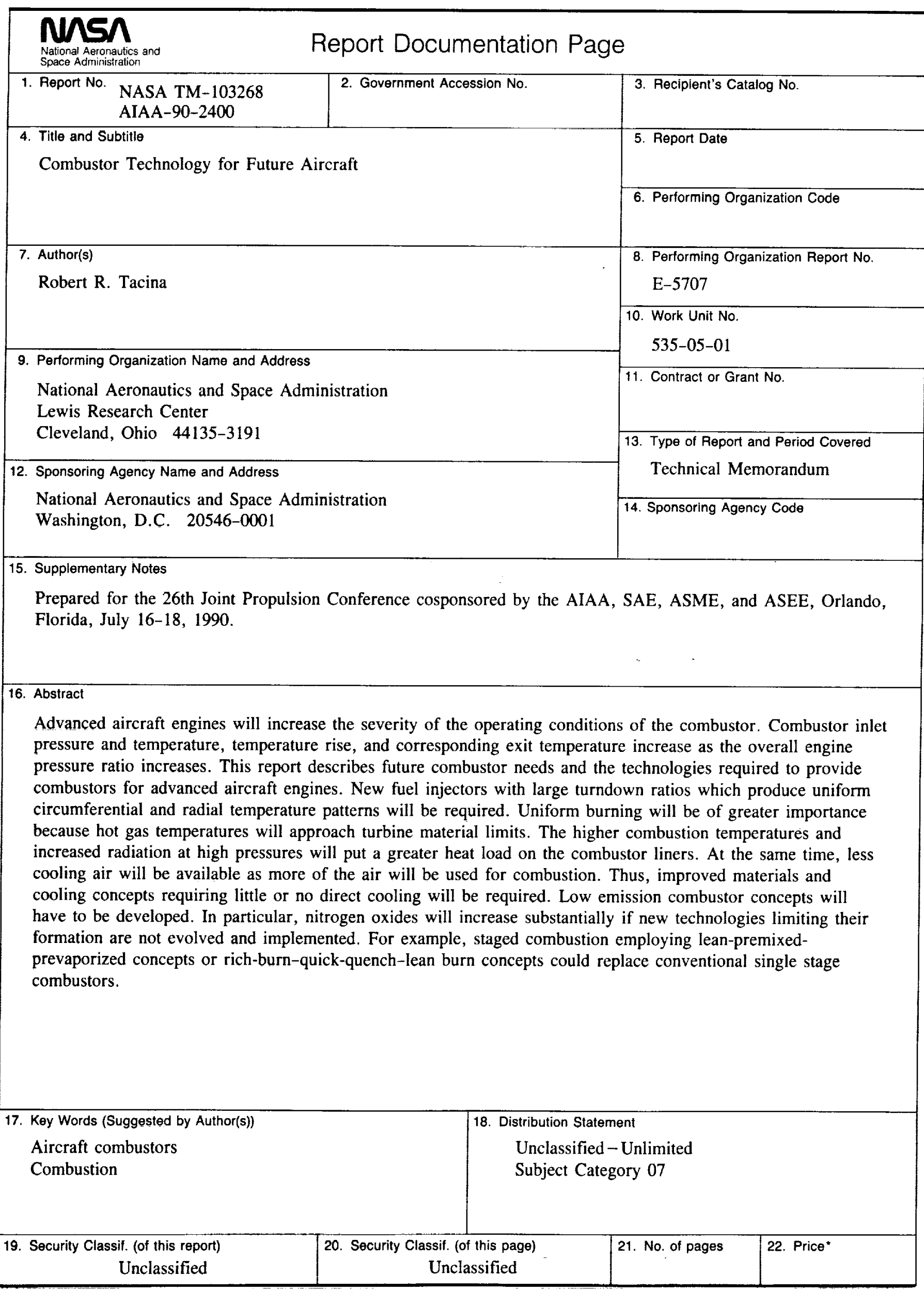

